\title{
Non-Medical Radiography Staff Experiences in Inter-Professional Communication: A Swedish Qualitative Focus Group Interview Study
}

This article was published in the following Dove Press journal: Journal of Multidisciplinary Healthcare

\author{
Nabi Fatahi (D) \\ Mirjana Kustrimovic ${ }^{2}$ \\ Helen Elden iD $^{3}$ \\ 'Department of Learning and Leadership \\ for Health Care Professionals, Institute of \\ Health and Care Sciences, The Sahlgrenska \\ Academy, University of Gothenburg, \\ Gothenburg, Sweden; ${ }^{2}$ Department of \\ Radiography, Institute of Health and Care \\ Sciences, The Sahlgrenska Academy, \\ University of Gothenburg, Gothenburg, \\ Sweden; ${ }^{3}$ Department of Reproductive and \\ Perinatal Health, Institute of Health and \\ Care Sciences, The Sahlgrenska Academy, \\ University of Gothenburg, Gothenburg, \\ Sweden
}

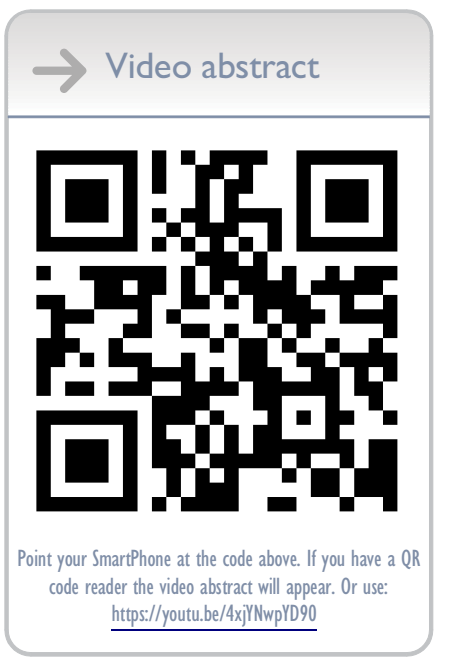

Correspondence: Nabi Fatahi Department of Radiology, Sahlgrenska University Hospital, Gothenburg 4I345, Sweden

Tel +46704383133

Fax +46317866002

Email nabi.fatahi@allmed.gu.se
Purpose: To describe the experiences of non-medical discipline staff of difficulties and possibilities in inter-professional communication within the radiology department and remitting departments.

Materials and Methods: Three focus group interviews were conducted with 16 nonmedical discipline staff in a radiology department at a university hospital in Sweden. Data were analysed using qualitative content analysis.

Results: The experiences of inter-professional communication by non-medical discipline staff within the radiology department and with remitting departments can be described in three categories, and six sub categories. The informants experienced difficulties in both oral and written inter-professional communication. Inadequate structures, incorrect information and unclear language in the referral forms, lack of feedback from clinicians and radiologists, and reduced face-toface communication were described as factors that negatively influenced communication. Other difficulties were time shortage, inadequate routines and economy issues. The possibilities described were use of face-to-face communication, interpreters, and clear and well-structured referral forms.

Conclusion: Non-medical staff experience that quality in inter-professional communication has a significant impact on health outcomes and patient safety. They expressed a number of difficulties in both written and oral inter-professional communication. For example inadequate written and oral communication, as well as practical issues such as routine could negatively influence the quality of the outcome of inter-professional communication. Lack of feedback from clinicians and radiologists and reduced face-to-face communication were also mentioned as factors that influence oral communication. Possibilities described to improve inter-professional communication quality and thus patient safety were professional contact on both professional and personal levels, use of interpreters, and clear and well-structured referral forms. The results of this study add to our knowledge of the difficulties and possibilities in non-medical interprofessional communication, which may enhance both safety and health outcomes for patients if implemented. Future studies in interprofessional communication is needed.

Keywords: face-to-face communication, interprofessional communication, oral communication, radiograph, radiologist, written communication

\section{Introduction}

Since adequate inter-professional communication and collaboration are considered key in improving patient safety, they should frequently be in the focus of attention. ${ }^{1}$ In order to achieve satisfactory health outcomes in patient care, appropriate interprofessional communication skills are crucial. ${ }^{2}$ According to previous studies ${ }^{3,4}$ 
improvements and enhancements to joint activities, such as seminars and workshops for professionals who are in frequent contact in the course of their duties, have a significant impact on their inter-professional work. Knowledge about the development of interaction between inter-professional healthcare staff and how it affects the quality of health outcomes, is considered important in cooperation between teams. ${ }^{5}$ Earlier studies of radiologists' experiences of interprofessional communication described difficulties such as insufficient information in the referral forms leading to the wrong radiography examination being performed ${ }^{4,6}$ Misunderstandings in both inter-personal and inter-professional clinical communication cause suffering in patients and economic losses in the healthcare system. The same researchers ${ }^{4,6}$ also described the decreased face-to face communication with patients due to high technology development. This is a problem since good interpersonal relationships and face-to-face communication with patients have been reported to lead to improvements in inter-professional communication and thus increased patient safety. ${ }^{6}$ A study in the United States $(n=437)$ showed that in $350 / 437,80 \%$ of malpractice consisted of cases of misunderstandings in family medicine. Forty-seven per cent of those $(n=165 / 350)$ consisted of incorrect diagnoses rooted in failures in inter-professional communication. ${ }^{7}$ Healthcare professionals who are familiar with traditional communication modes, face new challenges in inter-professional communication ${ }^{4}$ due to the introduction of electronic communication over recent decades. Working in an inter-professional context requires greater sensitivity to social issues within the team, and the willingness to share roles in developing cooperation and working methods to ensure patient safety. ${ }^{3,4}$ Also, according to previous research, the lack of time and interprofessional hierarchies have a significant impact on the quality of inter-professional communication. ${ }^{2,8}$ Poor interprofessional communication between healthcare staff in different disciplines could be considered as a potential source of insufficient health outcomes, which may threaten patient safety. In order to provide adequate health care to patients and increase patient safety factors, efficient and effective inter-professional communication is crucial. Since inter-professional communication and collaboration is a fundamental element in improving patient safety, satisfactory communication between non-medical healthcare staff is needed. Sufficient inter-professional communication among healthcare staff, not only orally, but also in writing, such as the correct documentation of patients' cases, are key factors that influence patient safety. $2,9,10$ Knowledge about inter-professional communication in non-medical radiography staff is lacking. The aim of this study was to describe the experience of non-medical discipline staff of difficulties and possibilities in interprofessional communication within the radiology department, and with remitting departments.

\section{Materials and Methods}

This research used qualitative content analysis ${ }^{11-13}$ in an inductive way. Qualitative content analysis has a long tradition within communication, journalism, sociology, business, and document analysis. ${ }^{14}$ It attempts to understand a specific context, and to reach nuanced descriptions surrounding different qualitative aspects of the interviewees' experiences of an observed phenomenon. ${ }^{15}$ It takes consideration of subjectivity and complexity, and seeks not to quantify or reduce, but represent the informants' rich, subjective experiences, and reflect the subtle and complex processes involved, while retaining the nuances of the data $^{16 .}$ Qualitative content analysis involves identifying, coding and categorising primary patterns emerging from the collected data.

Data was collected by focus group interviews. In comparison with individual interviews, focus group interviews are more capable of stimulating other member's opinions regarding the research subject being discussed. ${ }^{17}$ The study was performed in three radiography departments at Sahlgrenska University Hospital, which perform all kinds of radiography examinations. In all 524 members of staff work in the department, and patients are referred by the clinician on the hospital ward or the emergency ward. A written patient referral form is sent to the medical secretaries in the radiograph department, who register and schedule the examination. The referral form is then given to the radiographer who will perform the radiography examination on the patient. The medical secretary phones the ward were the patient is and informs them of the time for the examination. The patient arrives in the radiography department, and the radiographer and assistant radiographer use oral communication to explain the radiology examination process to the patient. The results of the examinations conducted are sent to the radiologist for diagnosis. The process ends when the examination results are sent by the radiologist to the medical secretary in order to communicate the results to the remitting clinicians. A report on the quality of work in the department is drawn up once a month and consists of reporting errors in 
the methods during examinations, patient satisfaction and registration of insufficient information in referral forms. Furthermore, the quality of the work in the department was reported once a month and consisted of errors in the methods used during examinations, patient satisfaction, and registration of insufficient information in referral forms, which written communication considered as a part of this quality control.

The inclusion criterion was: Non-medical radiography staff involved in oral and written interprofessional communication in the radiography departments at Sahlgrenska University Hospital. Informants were recruited through announcements in the participating radiography departments. The announcement included information about the purpose and voluntary nature of the study. Informants were assured that the data would be treated confidentially, and that they were free to withdraw at any time. Nonmedical radiography staff who were interested in participation in the study called NF or MK. They were informed further about the study and had the option to ask questions about participation. If they were interested, an appointment for the focus group interview was booked. Data were collected through three focus group discussions, which were performed at the hospital. In all, five nurse radiographers, six nurse radiographers' assistants and five medical secretaries were included in the study. They were 25 to 62 years of age (median 39 years), and had worked as radiography staff for two to 35 years (median 12 years).

The informants gave their written consent before the focus group interviews, which were carried out in line with the guidelines contained in the Helsinki Declaration (World Medical Association, 2004). The Regional Ethics Committee in Gothenburg, Sweden, approved the study in April 2017 (Reference number: 135-17).

The semi-structured focus group discussions ${ }^{18,19}$ were led by one of the authors (NF). This method allowed the informants to talk about issues that not been addressed in the main questions, and made it possible for them to talk about their experiences of the phenomenon. The interviews were conducted in their native language (Swedish), and began with two main questions: What is your experience of interprofessional communication, both oral and written, between the non-medical radiography staff and the referring clinicians? What are the difficulties, and possibilities in communication, and how can the difficulties be overcome? These questions were followed by more targeted questions from the mediators, whereby the discussion was developed until a rich variation of the studied phenomenon was gained.
The focus group interviews were audio-recorded and lasted 62, 56 and 70 mins respectively. Interviews were transcribed verbatim and analysed by qualitative content analysis according to Graneheim and Lundman (ref in). Two of the authors (NF, MK) independently read the transcribed discussions carefully and repeatedly, extracting meaning units that addressed specific topics, and compared, condensed, coded and categorized them into subcategories, categories and finally a theme. ${ }^{13}$

\section{Results}

The theme: The experiences of interprofessional communication in three categories (modes of communication; practical aspects, and suggestions for improvement), and six subcategories emerged (Table 1). Illustrative quotations are presented below.

\section{Modes of Communication Written Communication}

Written communication, in the form of paper referral forms or by electronic means, is often a source of misunderstanding between the radiography staff and other clinical personnel involved. Insufficient and incorrect information in referral forms, unstructured referral forms, as well as using unclear and unsatisfactory language are some of the problems highlighted by the informants in the present study. The consequences of unsatisfactory and incorrect information in written communication were expressed by some of the informants as follows:

Incorrect appointments for radiology examinations and incorrect examination codes often create problems for us. Sometimes they request more than one examination with the same code, which is impossible according to our system. They write the code for one examination but another examination is indicated in the text below in the referral form.

Insufficient information on referral forms about the patient, the type of examination and the mechanism of the trauma, as well as interpretation of referral forms, were other problems expressed by some of the informants in this study.

The interpretation of the text in the referral form is often time-consuming, because there are many members of staff who need to understand the referral form, sufficient information about patient case is crucial. 
Table I Theme and Categories Describing Non-Medical Disciplines Experiences of Inter-Professional Communication Within the Radiology Department and with Remitting

\begin{tabular}{|c|c|c|c|c|c|c|}
\hline \multirow{3}{*}{$\begin{array}{l}\text { Theme } \\
\text { Categories } \\
\text { Sub- } \\
\text { Categories }\end{array}$} & \multicolumn{6}{|c|}{ Experiences of Interprofessional Communication } \\
\hline & \multicolumn{2}{|c|}{ Different Modes of Communication } & \multicolumn{2}{|l|}{ Practical Aspect } & \multicolumn{2}{|l|}{ Patients' Safety } \\
\hline & $\begin{array}{l}\text { Written } \\
\text { Communication }\end{array}$ & $\begin{array}{l}\text { Oral } \\
\text { Communication }\end{array}$ & Routines & $\begin{array}{l}\text { Time and } \\
\text { Economy }\end{array}$ & $\begin{array}{l}\text { Communications' } \\
\text { Quality }\end{array}$ & $\begin{array}{l}\text { Suggestions } \\
\text { for } \\
\text { Improvement }\end{array}$ \\
\hline & $\begin{array}{l}\text { Inadequate } \\
\text { request forms } \\
\text { structure }\end{array}$ & $\begin{array}{l}\text { Unnecessary phone } \\
\text { calls }\end{array}$ & $\begin{array}{l}\text { Identification of } \\
\text { risk patients }\end{array}$ & $\begin{array}{l}\text { Time-consuming } \\
\text { request form }\end{array}$ & Lower quality & $\begin{array}{l}\text { Avoid careless } \\
\text { mistakes }\end{array}$ \\
\hline & $\begin{array}{l}\text { Insufficient } \\
\text { information }\end{array}$ & $\begin{array}{l}\text { Lack of direct } \\
\text { communication }\end{array}$ & $\begin{array}{l}\text { Safety to know } \\
\text { each other }\end{array}$ & Waste of time & disposing & $\begin{array}{l}\text { Lack of } \\
\text { commitment }\end{array}$ \\
\hline & $\begin{array}{l}\text { Incorrect } \\
\text { information in } \\
\text { request forms }\end{array}$ & $\begin{array}{l}\text { Direct } \\
\text { communication }\end{array}$ & $\begin{array}{l}\text { Insecure not to } \\
\text { know each other }\end{array}$ & $\begin{array}{l}\text { Change of } \\
\text { survey }\end{array}$ & Nursing & Interprofessional \\
\hline & $\begin{array}{l}\text { Incorrect } \\
\text { information }\end{array}$ & helps & $\begin{array}{l}\text { Easier to handle the } \\
\text { paper request } \\
\text { forms }\end{array}$ & Extra effort & Radiation safety & cooperation \\
\hline & $\begin{array}{l}\text { Insufficient } \\
\text { information }\end{array}$ & $\begin{array}{l}\text { Lack of personnel } \\
\text { contact }\end{array}$ & $\begin{array}{l}\text { Unclear whose } \\
\text { responsibility }\end{array}$ & $\begin{array}{l}\text { Time-consuming } \\
\text { tasks }\end{array}$ & Lack of security & $\begin{array}{l}\text { Better social } \\
\text { relationship }\end{array}$ \\
\hline & $\begin{array}{l}\text { Incorrect } \\
\text { information in } \\
\text { request forms }\end{array}$ & $\begin{array}{l}\text { Lack of direct } \\
\text { interprofessional } \\
\text { contact }\end{array}$ & Planned activity & $\begin{array}{l}\text { Unnecessary } \\
\text { effort }\end{array}$ & Dignity & Voluntary social \\
\hline & $\begin{array}{l}\text { Unclear language } \\
\text { in the request } \\
\text { forms }\end{array}$ & Extreme phone calls & Different routines & $\begin{array}{l}\text { Incorrect } \\
\text { information } \\
\text { requires time }\end{array}$ & $\begin{array}{l}\text { Interpreter is } \\
\text { important }\end{array}$ & contacts \\
\hline & Complex written & $\begin{array}{l}\text { Unnecessary } \\
\text { communication }\end{array}$ & $\begin{array}{l}\text { Lack of general } \\
\text { guidelines }\end{array}$ & $\begin{array}{l}\text { Availability by } \\
\text { phone }\end{array}$ & Staff as interprets & $\begin{array}{l}\text { Better private } \\
\text { relationships }\end{array}$ \\
\hline & Communication & $\begin{array}{l}\text { Complex } \\
\text { communication }\end{array}$ & Unnecessary tasks & Time-saving & $\begin{array}{l}\text { Clearer electricity } \\
\text { request forms } \\
\text { structure }\end{array}$ & $\begin{array}{l}\text { Clear language } \\
\text { in } \\
\text { communication }\end{array}$ \\
\hline & $\begin{array}{l}\text { Better electronic } \\
\text { communication }\end{array}$ & $\begin{array}{l}\text { Successful } \\
\text { interprofessional } \\
\text { communication }\end{array}$ & Unclear routines & Cost & High accessibility & \\
\hline & & Nice phone calls & Wrong priority & Economic issue & $\begin{array}{l}\text { Change of request } \\
\text { form appearance }\end{array}$ & \\
\hline & & & $\begin{array}{l}\text { Shared } \\
\text { responsibility }\end{array}$ & $\begin{array}{l}\text { Repeatedly } \\
\text { error orders }\end{array}$ & No interpreter exists & \\
\hline & & & & & Community & \\
\hline & & & & & $\begin{array}{l}\text { Correct examination } \\
\text { code }\end{array}$ & \\
\hline & & & & & $\begin{array}{l}\text { Interprofessional } \\
\text { understanding }\end{array}$ & \\
\hline
\end{tabular}




\section{Oral Communication (Phone Contact and Face-to-Face Communication)}

According to the results of the study, the oral form of interprofessional communication consists of discussion of cases, questions about unclear and insufficient information in referral forms, and appointments for examinations. These issues often come up in phone contact and face- to -face communication. The informants expressed the importance of oral communication frequently during the group discussions. Radiographers are concerned that as a result of digitalization in the radiology department, face-to-face contact with radiologists has been reduced dramatically over recent years. Radiographers mentioned that face-to-face contact between radiographers and radiologists is necessary for the quality of examinations, but also for enhancing skills in radiography.

"We often go to them when necessary but radiologists rarely come to us to give feedback".

The informants in the present study discussed the necessity of face-to-face inter-professional communication frequently during the group discussions. One of the informants expressed this necessity as follows:

"Social contact through direct communication is necessary not only for social reasons but also for the development of our profession".

Despite the problems highlighted by the informants regarding oral communication, such as unnecessary phone contact and sometimes a lack of feedback from radiologists, the majority of the informants expressed that they were more satisfied with oral than written communication.

"Direct communication helps us to understand each other better and avoid mistaken interpretations and conjectures".

\section{Practical Aspects \\ Routines}

The importance of an adequate routine for both professions' effectiveness and patient safety was clearly confirmed by the informants in the study. According to the results of the study, insufficient routines negatively affect all their activities. According to the results, adequate routines make it possible to identify patients at risk and make them a satisfactory priority, which is an important issue in terms of ethics. Due to limited healthcare resources, there are often long waiting times for patients coming to the radiology department for examinations. The results of the study show that wrong priorities may be a risk factor that affects health outcomes and patient safety. In this context it is quite important that both the radiologists and the referring clinicians set correct priorities so that patients at risk have the opportunity to have an examination before others.

"Different routines and lack of general guidelines lead to unnecessary time-wasting and workload" was expressed by one of the informants. According to the results, the way in which patients' case notes and imaging are prepared for radiology conferences, to provide patients with a preliminary answer, is a clear example of routine.

All radiological examinations must be included in radiology conferences and the doctor is required to write and sign a preliminary answer that is ready for printing. If the doctor does not sign it, we have to return it to the conference, which is time-consuming and troublesome.

\section{Time and Economy}

Time and economy were discussed frequently during the group discussions as factors that influence the quality of examinations, as well as patient safety. There is a strong connection between routines and time-wasting, if there is something wrong with the routine it leads to more timewasting than normal. "Incorrect information requires more time to understand". According to the results, incorrect written information from clinicians occurs frequently. Despite digitalization in the radiological department, which has generally led to a reduction in time-wasting, sometimes we need more time than before:

With digitalization, the referral form reaches our department faster than before, but we cannot do anything before getting the patient's entire information, sometimes the time required for referral form management becomes longer than before, when we were working traditionally.

According to radiography staff, economic factors may potentially affect communication between patients and staff. They mentioned that sometimes they come across non-Swedish- speaking patients, whose language level is not sufficient to communicate with staff. On the other hand they are not allowed to assign interpreters for all kind of examinations, so these cases could lead to misunderstandings in communication, which represents a risk for the quality of the examination and patient safety.

To assign an interpreter is an additional cost for the radiography department; it is actually those who order the radiological examinations who should pay for the interpreter. 


\section{Patient Safety Communication Quality}

The results indicate that a number of practical issues may influence the quality of communication. Careless mistakes, lack of commitment, incompetent interpreters, lack of inter-professional cooperation, as well as inadequate relationships between staff were mentioned as some of the factors that may negatively influence communication quality.

Any way my experience has shown that the case you mentioned is correct, sometimes it's difficult to have this communication when you don't know each other well enough

\section{Suggestions for Improvement}

In order to improve inter-professional communication and avoid misunderstandings, a number of activities were suggested by the informants in this study. To improve interpersonal relationships, and increase face-to-face contact, joint activities, such as workshops and seminars for staff from different professions involved in the same task, were suggested by informants in the present study. It was also suggested that feedback to the radiographer from radiologists should be facilitated in digital communication systems, and would prevent mistakes in their contact.

Apart from the suggestions mentioned above, the structure of the referral forms, correct examination codes and clear guidelines for routines and phone contact were addressed by informants as important issues for attention to improve communication. According to the results, without mutual understanding between radiography staff and the referring departments concerning patient preparation for radiological examinations, there is often a potential risk to patient safety. One of the informants mentioned that all information about patients and the actual examination is necessary, and patients must understand the information given by the radiography staff regarding the actual radiological examination. Otherwise, is it impossible to carry out the examination, which could led to suffering for the patient and economic loss for the health care system.

If the referring department sends a patient with limited language skills, they have to assign an interpreter before they send the patient to the radiology department for examination.

\section{Discussion}

\section{Comment on Method}

As the study was dealing with the quality of communication, qualitative content analysis as described by Griesheim and Landman was used. It is a well-known and recognized method considered appropriate to describe collected data. ${ }^{13}$ All the informants were from the same university hospital located in Sweden. As all personnel in the radiography department are involved in communication regarding radiological tests of patients, we decided to include informants from different professions in the radiography department.

Although the informants were working in the same hospital there were variations in terms of age, professions, job profiles, as well as the number of years of work experience. There are methodological considerations to be taken into account when interpreting and transferring results derived through the use of a qualitative method, such as the influence of the researcher during the interview, as well as during the process of analysis. ${ }^{18}$ On the other hand, it is possible that the participants felt safe, and shared more of their experience with someone who recognized the situation they were describing. ${ }^{13}$

A strength of this method is that the researchers tried to describe the steps in the analysis as clearly as possible, to enable the readers to follow and understand the process of analysis. The analysis was critically discussed and compared by all the authors, moving back and forth between the entire text, and subcategories and categories to enhance credibility. However, this study had several limitations. For instance, there was no balance in variation of gender ( 2 men and 14 women) and all the informants were from the same region in Sweden and had the same culture. Although, according to the literature concerning focus group interviews ${ }^{20}$ the size of our focus groups was acceptable (a sample of four to twelve focus groups) the number of focus groups was small. Also, two of the authors (NF and MK) have long experience of working in a radiography department. Pre-understanding based on long experience may have a negative influence when gathering data and carrying out analyses in qualitative research. However, the researchers were aware of this early on, and constant verification by a co-author (HE) without this experience, counterbalanced this pre-understanding, enabling exploration and discussion of the data in a balanced manner.

\section{Comment on Result}

The results of the study revealed that inadequate written and oral communication, as well as practical issues, could 
influence the quality of the communication outcome. Quality in inter-professional communication may have a significant impact on health outcomes and patient safety. This finding supports previous studies, indicating that inter-professional collaboration and relationships, as well as communication skills and strategy, are essential to adequate health outcomes and patient safety. ${ }^{21,22}$ However, a limitation is that the results must be interpreted in relation to context. The fact that qualitative findings are contextual does not mean they have no meaning in other contexts, but must be related to the new context when findings are transferred. ${ }^{18}$

\section{Modes of Communication}

Informants in this study described their experience of several problems in both written and oral inter-professional communication. Even though some problems were indicated in oral inter-professional communication, difficulties were most frequent in inter-professional written communication. In this context, the inadequate structure of referral forms, insufficient information and incorrect information, and unclear language in the referral forms were highlighted as difficulties. Lack of feedback from clinicians and radiologists, and reduced face-to -face communication were also mentioned as factors that negatively influenced oral communication. In order to reduce inter-professional communication errors, intensive simulation-enhanced training for inter-professional teams is crucial. ${ }^{23}$ Effective and adequate interpersonal and interprofessional communication, co-operation, and co-ordination in teamwork, have not only a significant impact on health outcomes and patient safety, but also reduce stress in both professional and personal life. ${ }^{24,25}$

\section{Practical Aspects}

Besides the human factors that influence inter-professional communication, the practical issues also have an important role in this context. Proper routines and appropriate cooperation are fundamental elements when working across professional boundaries. The fact that an adequate routine reinforces teamwork in an inter-professional context, and that it contributes to patient safety, has been confirmed by previous studies. ${ }^{8,9,26}$ Unclear routines, such as in the way in which patients' case notes and imaging are prepared for radiology conferences to provide patients with a preliminary answer, differences in routines, lack of attention to patient case priorities, wrong priorities, a lack of general guidelines for contact, and unclear responsibilities for different tasks, were some of the problems highlighted by the informants in this study.
A standard routine in all radiography departments concerning the examination process, from the patients' registration to determination of diagnosis, is vital.

Apart from routines, the time aspect and questions of economy were other influential factors discussed by the informants in the group discussions. Failures in communication, such as incorrect information on referral forms, incorrect patient priorities, unnecessary phone contact and other time-consuming tasks, frequently led to a lack of time. The importance of reasonable timeframes in all types of clinical communication was confirmed by previous studies. ${ }^{27,28}$ In order to save money, failure to assign an interpreter, although the patient and radiography staff do not share the same language, may lead to a significant errors in documentation of patient anamneses. Moreover, lack of time during the communications process may also result in stress for radiography staff. In both cases, communication may be negatively affected and could lead to misunderstandings, which affects patient safety.

\section{Patient Safety}

According to our results, the informants expressed that, apart from the quality of inter-professional communication, unsatisfactory interpersonal communication in cases where the patient and staff do not speak the same language could be considered as a potential source of misunderstanding. To prevent miscommunication, protect the patients' safety and improve the health outcomes in cases where a third person (interpreter) is involved as a language link, the interpreting quality must be the focus of attention. ${ }^{29,30}$ The quality of communication is a fundamental element in the quality of health outcome and patient safety. Apart from factors related to the mode of communication (written or oral communication), the quality of health outcomes may also be influenced by practical issues, such as inter-professional relationships, collaboration and cooperation. ${ }^{28}$

In order to improve communication quality and patient safety, the informants mentioned possibilities related to the need for sufficient inter-professional contact on both professional and personal levels, the use of interpreters, and clear and well-structured referral forms. Better electronic systems for communication and protection of patients from unnecessary radiation were also mentioned by the informants, which is in line with the results of a previous study. ${ }^{4}$

\section{Conclusion}

The results of the study revealed that non-medical staff experience that quality in inter-professional communication 
has a significant impact on health outcomes and patient safety. The informants expressed a number of difficulties in both written and oral inter-professional communication. For example: inadequate written and oral communication, as well as practical issues that could negatively influence the quality of the inter-professional communication outcome. Lack of feedback from clinicians and radiologists, and reduced face-to-face communication were mentioned as factors that influenced oral communication. Possibilities described to improve inter-professional communication quality, and thus patient safety, were professional contact on both interprofessional, and interpersonal levels, use of interpreters in cases of a language barrier, and clear and well-structured referral forms. We believe that the study results increase knowledge of difficulties and possibilities in non-medical inter-professional communication, which may enhance both safety and health outcomes for the patients if implemented. Future studies should be conducted relating to interprofessional communication, in both oral and written modes.

\section{Disclosure}

The authors report no conflict of interest in this work.

\section{References}

1. Foronda C, MacWilliams B, McArthur E. Interprofessional communication in healthcare: an integrative review. Nurs Educ Pract. 2016;19:36-40. doi:10.1016/j.nepr.2016.04.005

2. Rice K, Zwarenstein M, Conn LG, Kenaszchuk C, Russell A, Reeves S. An intervention to improve interprofessional collaboration and communications: a comparative qualitative study. $J$ Interprof Care. 2010;24:350-361. doi:10.3109/13561820903550713

3. Franz S, Muser J, Thielhorn U, Wallesch CW, Behrens J. Interprofessional communication and interaction in the neurological rehabilitation team: a literature review. Disabil Rehabil. 2018;20:1-9. doi:10.1080/09638288.2018.1528634

4. Fatahi N, Krupic F, Hellström M. Quality of radiologists' communication with other clinicians-as experienced by radiologists. Patient Educ Couns. 2015;98:722-727. doi:10.1016/j.pec.2015.02.009

5. Shoham DA, Harris JK, Mundt M, McGaghie W. A network model of communication in an interprofessional team of healthcare professionals: a cross-sectional study of a burn unit. $J$ Interprof Care. 2016;30:661-667. doi:10.1080/13561820.2016.1203296

6. Sharma U, Klocke D. Attitudes of nursing staff toward interprofessional in-patient-centered rounding. Interprof Care. 2014;28:475-477. doi:10.3109/13561820.2014.907558

7. Fernald DH, Pace WD, Harris DM, West DR, Main DS, Westfall JM. Event reporting to a primary care patient safety reporting system: a report from the ASIPS collaborative. Ann Fam Med. 2004;2:327-332. doi:10.1370/afm.221

8. Fatahi N, Hellström M, Skott C, Mattsson B. General practitioners' views on consultations with interpreters: a triad situation with complex issues. Scand J Prim Health Care. 2008;26(1):40-45. doi:10.1080/ 02813430701877633
9. Burgener AM. Enhancing communication to improve patient safety and to increase patient satisfaction. Health Care Manag (Frederick). 2017;36(3):238-243. doi:10.1097/HCM.0000000000000165

10. Lancaster G, Kolakowsky-Hayner S, Kovacich J, Greer-Williams N. Interdisciplinary communication and collaboration among physicians, nurses, and unlicensed assistive personnel. J Nurs Scholarsh. 2015;47 (3):275-284. doi:10.1111/jnu.12130

11. Hsieh H, Shannon S. Three approaches to qualitative content analysis. Qual Health Res. 2005;15(9):1277-1288. doi:10.1177/ 1049732305276687

12. Elo $\mathrm{S}$, Kyngas $\mathrm{H}$. The qualitative content analysis process. $J A d v$ Nurs. 2008;62(1):107-115. PMid: 18352969. doi:10.1111/j.13652648.2007.04569.x

13. Graneheim U, Lundman B. Qualitative content analysis in nursing research: concepts, procedures and measures to achieve trustworthiness. Nurs Educ Today. 2004;24(2):105-112. doi:10.1016/j.nedt.2003.10.001

14. Krippendorf K. Content Analysis, an Introduction to Its Methodology. Second ed. Thousand Oaks, USA: Sage.

15. Dearnley C. A reflection on the use of semi-structured discussion. Nurs Res. 2005;13:19-28. doi:10.7748/nr2005.07.13.1.19.c5997

16. Brom A. Using qualitative interviews in CAM research: a guide to study design, data collection and data analysis. Complement Ther Med. 2005;13(1):65-73. PMid:15907681. doi:10.1016/j.ctim.2005.01.001.

17. McLafferty I. Focus group interviews as a data collecting strategy. $J$ Adv Nurs. 2004;48(2):187-194. doi:10.1111/jan.2004.48.issue-2

18. Morgan DL. Focus Group as Qualitative Research. 2nd ed. London: International Educational and Professional Publisher; 1997.

19. Tang KC, Davis A. Critical factors in determination of focus group size. Fam Pract. 1995;12:474-475. doi:10.1093/fampra/12.4.474

20. Barriball KL, While A. Collecting data using a semi-structured interview: a discussion paper. $J$ Adv Nurs. 1994;19(2):328-335. doi:10.1111/jan.1994.19.issue-2

21. Salvatori P, Mahoney P, Delottinville C. An interprofessional communication skills lab: a pilot project. Educ Health (Abingdon). 2006;19:380-384. doi:10.1080/13576280600938653

22. Eisenmann D, Stroben F, Gerken JD, Exadaktylos AK, Machner M, Hautz WE. Interprofessional emergency training leads to changes in the workplace. West J Emerg Med. 2018;19:185-192. doi:10.5811/ westjem.2017.11.35275

23. Vertino KA. Effective interpersonal communication: a practical guide to improve your life. Online J Issues Nurs. 2014;19:1. doi:10.3912/ OJIN.Vol19No03Man01

24. Gluyas H. Effective communication and teamwork promotes patient safety. Nurs Stand. 2015;29:50-57. doi:10.7748/ns.29.49.50.e10042

25. Tawfik DS, Sexton JB, Adair KC, Kaplan HC, Profit J. Context in quality of care: improving teamwork and resilience. Clin Perinatol. 2017;44(3):541-552. doi:10.1016/j.clp.2017.04.004.

26. Rydenfält C, Odenrick P, Larsson PA. Organizing for teamwork in healthcare: an alternative to team training? J Health Organ Manag. 2017;15:347-362. doi:10.1108/JHOM-12-2016-0233

27. Hemsley B, Balandin S, Worrall L. Nursing the patient with complex communication needs: time as a barrier and a facilitator to successful communication in hospital. $J$ Adv Nurs. 2012;68:116-126. doi:10.1111/j.1365-2648.2011.05722

28. Thistlethwaite JE. Collaboration, cooperation, communication, contact and competencies. GMS J Med Educ. 2016;29:33-37. doi: $10.3205 / \mathrm{zma} 001036$

29. Fatahi N, Nordholm L, Mattsson B, Hellström M. Experiences of Kurdish war-wounded refugees in communication with Swedish authorities through interpreter. Patient Educ Couns. 2010;78:160-165. doi:10.1016/j.pec.2009.03.010

30. Moreno MR, Otero-Sabogal R, Newman J. Assessing dual-role staff-interpreter linguistic competency in an integrated healthcare system. J Gen Intern Med. 2007;22:331-335. doi:10.1007/s11606007-0344-8 


\section{Publish your work in this journal}

The Journal of Multidisciplinary Healthcare is an international, peerreviewed open-access journal that aims to represent and publish research in healthcare areas delivered by practitioners of different disciplines. This includes studies and reviews conducted by multidisciplinary teams as well as research which evaluates the results or conduct of such teams or healthcare processes in general. The journal

covers a very wide range of areas and welcomes submissions from practitioners at all levels, from all over the world. The manuscript management system is completely online and includes a very quick and fair peer-review system. Visit http://www.dovepress.com/testimonials. php to read real quotes from published authors. 